\title{
Drag and lift force analysis for the cybertruck Tesla vehicle
}

\section{Análisis de fuerzas de arrastre y sustentación para el vehículo Tesla Cybertruck}

HORTELANO-CAPETILLO, Juan Gregorio ${ }^{1} \dagger^{*}$, MARTÍNEZ-VÁZQUEZ, J. Merced ${ }^{1}$, BAÑOSLOPEZ, Esperanza ${ }^{2}$ and ALFARO-AYALA J. Arturo ${ }^{3}$

\author{
${ }^{1}$ Universidad Politécnica de Juventino Rosas \\ ${ }^{2}$ Universidad Autónoma del Estado de Hidalgo \\ ${ }^{3}$ Universidad de Guanajuato \\ ID $1^{\text {st }}$ Author: J. Gregorio, Hortelano-Capetillo / ORC ID: 0000-0002-3702-4853 \\ ID $1^{\text {st }}$ Coauthor: J. Merced, Martínez-Vázquez / ORC ID: 0000-0002-6230-3846 \\ ID $2^{\text {nd }}$ Coauthor: Esperanza, Baños-Lopez / ORC ID: 0000-0003-3983-4507 \\ ID $3^{\text {rd }}$ Coauthor: J. Arturo, Alfaro-Ayala / ORC ID: 0000-0003-3081-282X
}

DOI: $10.35429 / J T E N .2021 .15 .5 .9 .16$

Received March 14, 2021; Accepted June 29, 2021

\begin{abstract}
In this research, aerodynamic tests were carried out at different speeds by using Solidworks Flow Simulation software in the Tesla Cybertruck vehicle, knowing the results of the drag and lift coefficients. The method was selected in three dimensions, the continuity equations and the Navier-Stokes equations that were solved by the finite volume method, the $\mathrm{k}-\varepsilon$ model was chosen to close the amounts of turbulence.
\end{abstract}

Drag coefficient, Lift coefficient, $\begin{aligned} & \text { Coeficiente de arrastre, Coeficiente de } \\ & \text { sustentación, Aerodinámica }\end{aligned}$
Aerodynamics

\section{Resumen}

En esta investigación se realizaron pruebas aerodinámicas a diferentes velocidades mediante el uso del software Solidworks Flow Simulation en el vehículo Tesla Cybertruck, conocer los resultados de los coeficientes de arrastre y sustentación. El método fue seleccionado en tres dimensiones, las ecuaciones de continuidad y las de Navier-Stokes que fueron resueltas por el método de volumen finito, el modelo $k-\varepsilon$ fue elegido para cerrar las cantidades de turbulencia.

\footnotetext{
* Correspondence to Author (e-mail: jhortelano_ptc@ upjr.edu.mx)

$\dagger$ Researcher contributing as first author.
} 


\section{Introduction.}

The Testa cybertruck shown in the Figure 1, was introduced in November 2019 that will be more useful than a traditional Pick-Up truck and will have a greater performance than a sport car, with a new class of resistance, speed, and versatility with a design fully electric. The powerful transmission and low center of gravity provide extraordinary traction and torque control. Allowing acceleration to go from 0 to 60 $\mathrm{mph}$ in just 2.9 seconds [1].

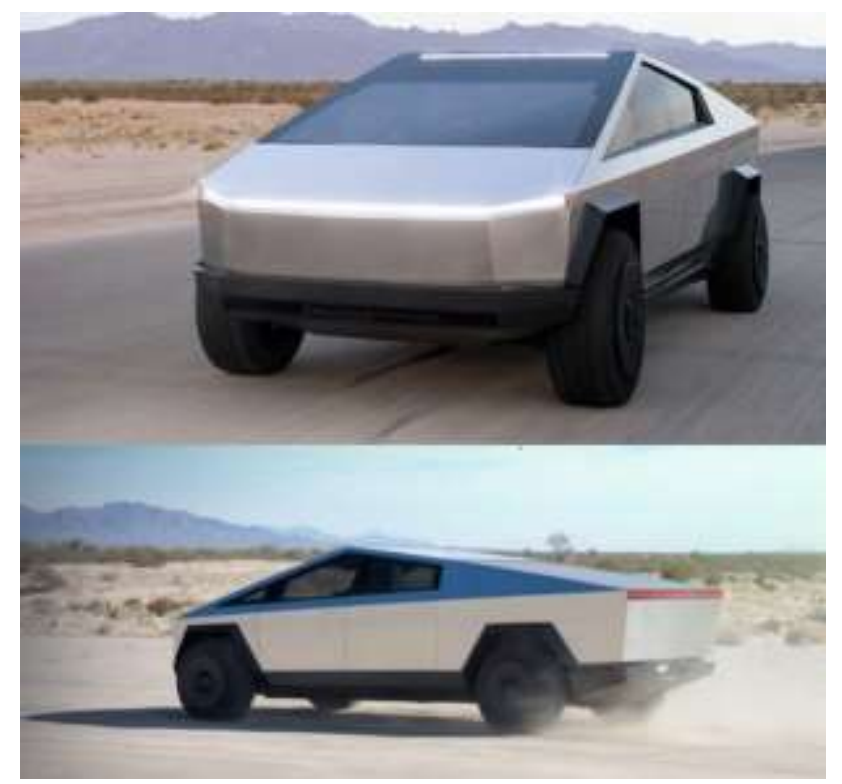

Figure 1 Tesla Cybertruck

Fuente: [1]

The first truck Pick-Up was built by brothers John and Horace Dodge during first world war under the name of Dodge Brothers [2], the first Chevrolet Pick-Up was called 490 Light Delivery with 4 cylinders of $21.7 \mathrm{Hp}$ [3], Ford began to market its Pick-Up called Ford T Runabout [4]. Improving aerodynamics consists of reducing the drag and lift forces of a vehicle because it is related to fuel consumption.

A $1 \%$ reduction in the drag coefficient would equal a significant saving in fuel cost $[4,5]$. In terms of environtmental impact, the reduction of $\mathrm{CO}_{2}$ emissions in recent decades has been one of the main objectives for the design of the most efficient vehicles. An estimated average with the most aerodynamic cas has a fuel saving of around 3-4\% due to reduction in the drag coefficient of $10 \%[7,8]$. Katz [9] and Regert et al. [10] proved that the drag force and the pressure distribution around the vehicle depend on the design and not on the friction of the surface.
The aerodynamics of Pick-Up trucks are more complex and have a coefficient of drag $15 \%$ higher than sport car and $25 \%$ higher than sedan vehicle [11]. Al-Garni et al. [12] observed that the coefficient of drag is high in a Pick-Up because of the complex interaction of the separate flow and the body, body walls, and tailgate that form a separate shear layer behind the cab. Holloway et al. [13] observed that the layer forms on the rear Pick-Up trucks, the Flow contains recirculating fluxes, unstable vortex shedding and other complex interactions.

All this phenomenon is of great interest for the aerodynamics of the truks, the losses at normal speed reach $60-70 \%$ of the total losses [14-16]. The drag force is the aerodynamic force that opposes movement, it is generated by the interaction and contact of a solid body with a fluid such as air. There are many factors that affect the magnitude of the drag force such as: the viscosity of the air and the viscous forces expressed to the movement such as the Reynolds number generating a flow limit layer along the solid surface [17]. The lift force is produced when cars travel at a high speed that causes the car to be unstable, this forcé is produced upwards. Therefore, the cars must be designed to reduce that lift force or implement some aerodynamic devices [17]. Figure 2 shows the different values of the drag coefficients $(\mathrm{Cd})$ and lift $(\mathrm{Cl})$ according to the shape and size for different aerodynamic profiles [18].

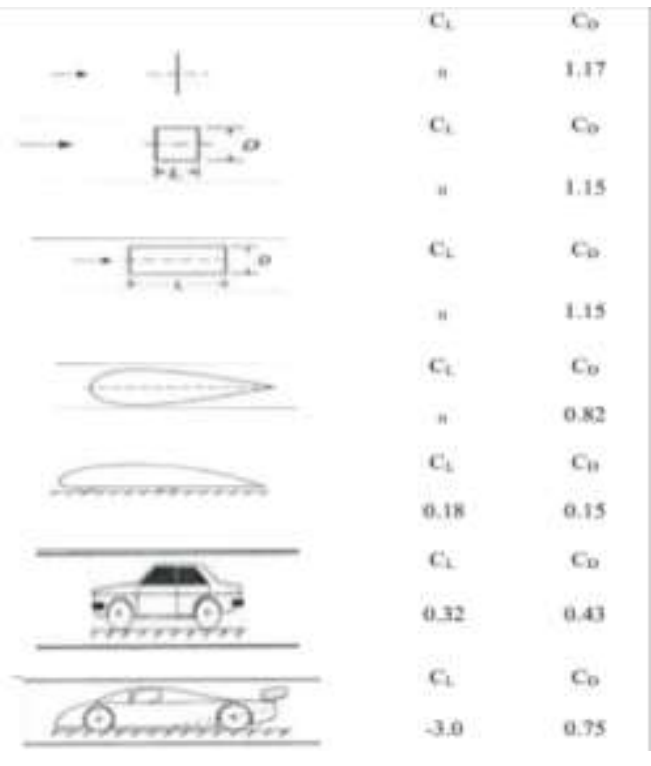

Figure 2 Drag $(\mathrm{Cd})$ and lift $(\mathrm{Cl})$ coefficients for different aerodynamic profiles [18] 
Figure 3 shows a comparison of the drag coefficients for different car models, a modern car achieves an average drag coefficient of 0.250.33 so that the aerodynamics obtain better performance.

In this research work, it will be demonstrated if the Tesla Cybertruck has excellent aerodynamics by calculating the drag and lift coefficients, later comparing it with data found in the literature as mentioned in Figure 3.

\section{Mathematical and numerical model}

CFD uses what is known as the finite element method, it is an approximation method used for solving fluid mechanics equations. Obtaining values of force, moments pressures, resistance to movement, etc., wich is the information obtained in a wind tunnel. In this work, several CFD tests were carried out to reproduce the aerodynamic behavior of the Tesla Cybertruck. Figure 4 shows the steps to solve a problem using CFD.

\begin{tabular}{|l|l|}
\hline \multicolumn{1}{|c|}{ Car } & CX \\
\hline Venturi VBB-3 (2013) & 0,13 \\
\hline Volkswagen XL1 (2013) & 0,189 \\
\hline Tesia Model S (2012) & 0,24 \\
\hline Opel Insignia (2009) & 0,27 \\
\hline Audi A3 (2003) & 0,32 \\
\hline Audi A6 (1997) & 0,28 \\
\hline Opel Kadett (1989) & 0,38 \\
\hline BMW Serie 1 (2004) & 0,31 \\
\hline Citroēn CX (1974) & 0,36 \\
\hline Citroēn C4 coupe & 0,28 \\
\hline Opel Astra (2004) & 0,32 \\
\hline Peugeot 807 (2002) & 0,33 \\
\hline Renault Espace (1997) & 0,36 \\
\hline Renault Espace (2002) & 0,35 \\
\hline Renault Vel Satis (2002) & 0,33 \\
\hline Hispano Divo (2003) & 0,55 \\
\hline Irizar PB (2002) & \\
\hline & 0,349 \\
\hline
\end{tabular}

Figure 3 Drag coefficients (Cd) for different car designs [19]
- $\quad$ Geometry modeling: The first step is to design the parto or object that you want to study generated in $\mathrm{CAD}$, for this case study, it is shown in Figure 5.

- $\quad$ Mesh generation: The CFD simulation is based on finite volumes, it is necessary to divide the model into small volumes, this known as meshing shown in Figure 7.

- $\quad$ Define models: In this step, the equations that the software will solve in the simulation are chosen continuity equation, Navier-Stokes equations, and turbulence models.

- $\quad$ Set properties: Define materials and their characteristics, fluids in the state they are, the air was selected for aerodynamic tests.

- Boundary conditions: The entry conditions must be specified, for this case different speeds were selected; and the boundary conditions the atmospheric pressure was selected.

- $\quad$ CFD simulations: Once the solid and the fluid have been perfectly selected, the simulation is carried out to obtain the convergence of the solution, the good behavior of the iterative process through residual diagrams.

- Results: Extract graphics, tables, videos, pressure contour, speed, temperature, streamlines, animations, etc.

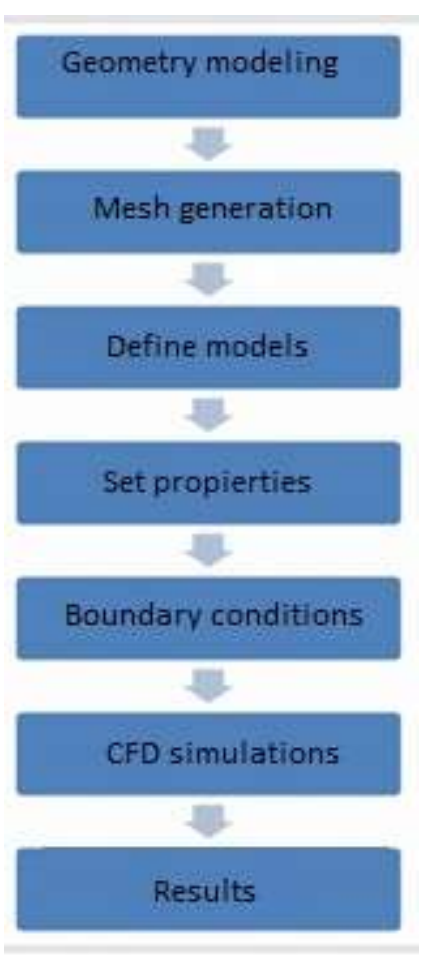

Figure 4 Steps for simulation in CFD Source: Own Elaboration 
The Tesla Cybertruk model is shown in Figures 5 and 6. Different views are observed, such as the front, side, rear, etc. The model was designed in Solidworks, later the aerodynamic simulations were carried out using the Flow Simulation plug-in. For an external aerodynamic analysis of a body, some coefficients must be considered, including the drag coefficient and the lift coefficient.

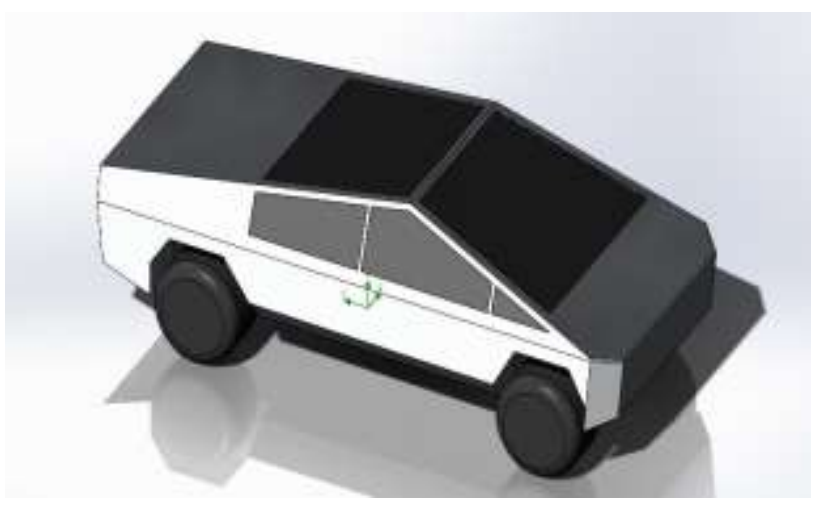

Figure 5 Design of the Tesla Cybertruck in Solidworks Source: Own Elaboration

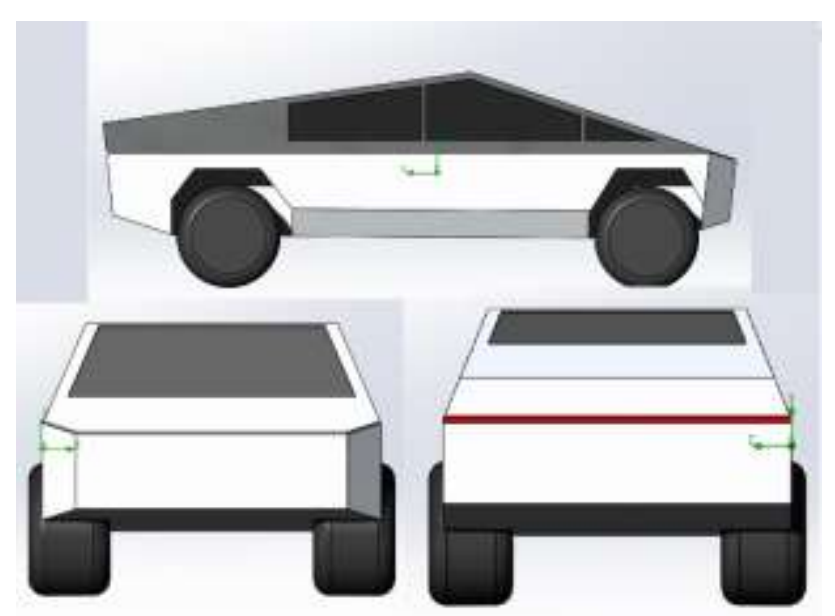

Figure 6 Design of Tesla Cybertruck in Solidworks, side, front, rear view

Source: Own Elaboration

Figure 7 show the control volume with 6043418 cells in the mesh made in Solidworks. The mesh is an important step for analysis in design, the software creates elements connected at points called nodes in Flow Simulation in hexahedral form, mesh control lets you specify different sizes of component elements, faces, edges, and vertices. The software creates a global element size for the model taking into account its volume, surface areas, and geometric details.

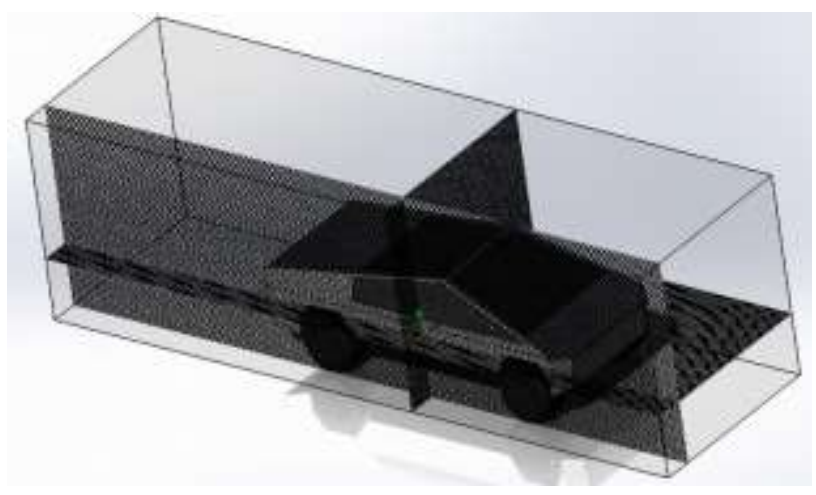

Figure 7 Control volume with 6043418 cells in the mesh Source: Own Elaboration

Figure 8 shows the dimensions of the Tesla Cybertruck made in Solidworks in scale where it has a length of $1180 \mathrm{~mm}$, height of 400 $\mathrm{mm}$ and width of $715 \mathrm{~mm}$.

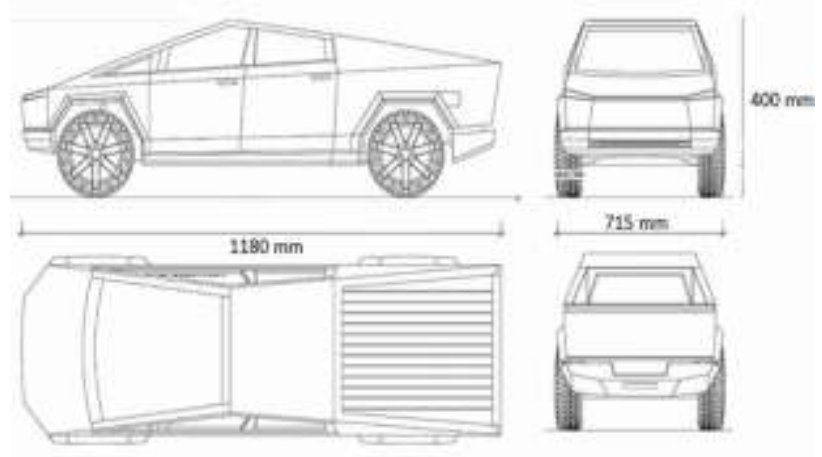

Figure 8. Tesla Cybertruck dimensions Source: Own Elaboration

The aerodynamic study that presents the Flow developed around the vehicles requires a mathematical presentation, which in turn is transformed into an algorithm for its solution. This mathematical model is summarized in a set conservation equation of mass, momentum, and the turbulence model k- $\varepsilon$.

The continuity equation is represented by [20]:

$\frac{\partial u}{\partial x}+\frac{\partial v}{\partial y}+\frac{\partial w}{\partial z}=0$

The Navier Stokes equations are expressed by [20]:

$\rho\left(\frac{\partial u}{\partial t}+u \frac{\partial u}{\partial x}+v \frac{\partial u}{\partial y}+w \frac{\partial u}{\partial z}\right)=\rho g_{x}-\frac{\partial P}{\partial x}+$

$\mu\left(\frac{\partial^{2} u}{\partial x^{2}}+\frac{\partial^{2} u}{\partial y^{2}}+\frac{\partial^{2} u}{\partial z^{2}}\right)$ 
$\rho\left(\frac{\partial v}{\partial t}+u \frac{\partial v}{\partial x}+v \frac{\partial v}{\partial y}+w \frac{\partial v}{\partial z}\right)=\rho g_{y}-\frac{\partial P}{\partial y}+$

$\mu\left(\frac{\partial^{2} v}{\partial x^{2}}+\frac{\partial^{2} v}{\partial y^{2}}+\frac{\partial^{2} v}{\partial z^{2}}\right)$

$\rho\left(\frac{\partial w}{\partial t}+u \frac{\partial w}{\partial x}+v \frac{\partial w}{\partial y}+w \frac{\partial w}{\partial z}\right)=\rho g_{z}-\frac{\partial P}{\partial z}+$

$\mu\left(\frac{\partial^{2} w}{\partial x^{2}}+\frac{\partial^{2} w}{\partial y^{2}}+\frac{\partial^{2} w}{\partial z^{2}}\right)$

For turbulent flows the Standard $k-\varepsilon$ model applies [21]:

$$
\begin{aligned}
& \frac{\partial}{\partial t}(\rho k)+\frac{\partial}{\partial x_{i}}\left(\rho k u_{i}\right)=\frac{\partial}{\partial x_{j}}\left[\left(\mu+\frac{\mu_{t}}{\sigma_{k}}\right) \frac{\partial k}{\partial x_{j}}\right]+ \\
& G_{k}+G_{b}-\rho \varepsilon-Y_{m}+S_{k} \\
& \frac{\partial}{\partial t}(\rho \varepsilon)+\frac{\partial}{\partial x_{i}}\left(\rho \varepsilon u_{i}\right)=\frac{\partial}{\partial x_{j}}\left[\left(\mu+\frac{\mu_{t}}{\sigma_{\varepsilon}}\right) \frac{\partial \varepsilon}{\partial x_{j}}\right]+ \\
& C_{1 \varepsilon} \frac{\varepsilon}{k}\left(G_{k}+C_{3 \varepsilon} G_{b}\right)-C_{2 \varepsilon} \rho \frac{\varepsilon^{2}}{k}+S_{\varepsilon}
\end{aligned}
$$

In these equations, $G_{k}$ represents the generation of turbulence kinetic energy due to average velocity gradients. $G_{b}$ is the generation of turbulent kinetic energy due to flotation. $\mathrm{Y}_{\mathrm{m}}$ represents the contribution of fluctuating dilation in compressible turbulence for all dissipation rates. $C_{1 \varepsilon}, C_{2 \varepsilon}$ and $C_{3 \varepsilon}$ are constant. $\sigma_{k}$ and $\sigma_{\varepsilon}$ are the turbulent Prantl numbers for $k$ and $\varepsilon$ respectively. $S_{\mathrm{k}}$ y $S_{\varepsilon}$ are user defined source terms. Turbulent viscosity $\mu_{\mathrm{t}}$ is calculated by:

$\mu_{t}=\rho C_{\mu} \frac{k^{2}}{\varepsilon}$

The parameters of some constants are:

$\mathrm{C}_{1 \varepsilon}=1.44, \mathrm{C}_{2 \varepsilon}=1.92, \mathrm{C}_{\mu}=0.09, \sigma_{\mathrm{k}}=1.0, \sigma_{\varepsilon}=1.3$

To calculate the drag coefficient, equation (7) is used, where $F_{x}$ is the drag force (N), $\rho$ is the air density $\left(\mathrm{kg} / \mathrm{m}^{3}\right), v$ is the air speed $(\mathrm{m} / \mathrm{s})$ and $A$ is the front area of the car [20], for this study the area is $0.286 \mathrm{~m}^{2}$.

$C d=\frac{F x}{(1 / 2) \rho v^{2} A}$

The lift force as perceived from its inception is normal to the ground. Equation (8) shows the calculation of the lift coefficient, where $F_{y}$ is the lift force:

$$
C l=\frac{F y}{(1 / 2) \rho v^{2} A}
$$

Fort he análisis of this work, air is used at speed of 80, 100, 120, 140, 160, 175, 200, 225 and $250 \mathrm{~km} / \mathrm{h}$ with a mesh number of 6043418 , the density of air is $1.2 \mathrm{~kg} / \mathrm{m}^{3}$ and the viscosity $1.8 \times 10^{-5}$ Pa.s.

With the results of the simulations, it is intended to know the drag and lift forces, later to calculate the coefficients to know the best aerodynamic model with the spoiler implemented in the rear that reduces these forces compared to normal models.

\section{Results}

Figure 9 shows the results of the drag forces $\left(\mathrm{F}_{\mathrm{x}}\right)$ and lift $\left(\mathrm{F}_{\mathrm{y}}\right)$ at speeds of 80, 100, 120, 140, 160, $175,200,225$ and $250 \mathrm{~km} / \mathrm{h}$ obtained through simulations in Solidworks, it is observed that the results of the forces increase as the speed increase.

Once the drag and lift force were obtained, the drag a lift coefficient shown in Figure 10 were calculated, it is observed that the drag coefficient has a range of $0.22-0.227$ and the lift coefficient of 0.11-0.117 at different speeds. Therefore, the coefficients remain constant when the speed is increasing.

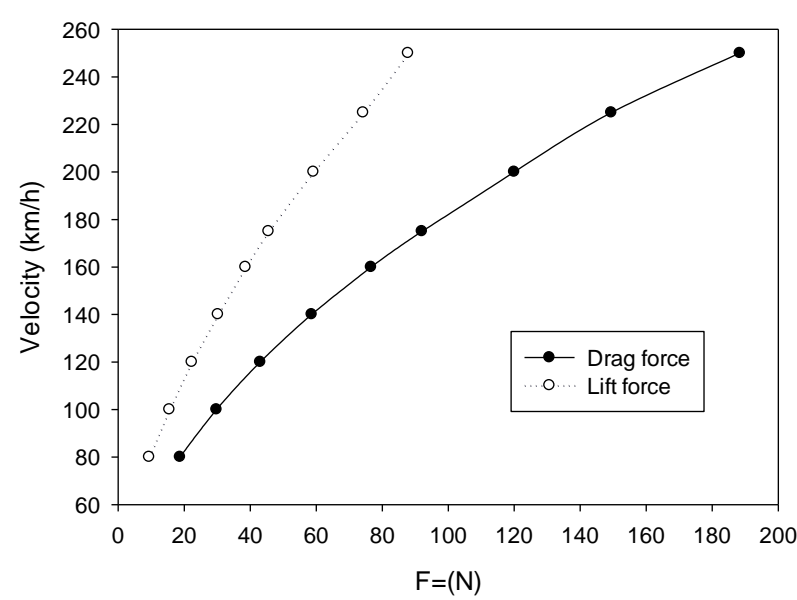

Figure 9 Results of the drag and lift forces obtained in Solidworks simulation Source: Own Elaboration 


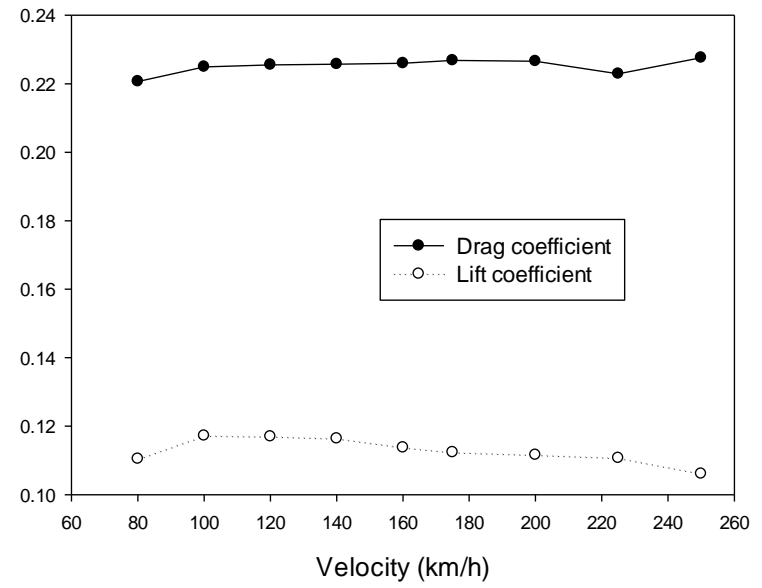

Figure 10 Results of the drag and lift coefficients obtained in Solidworks simulation

Source: Own Elaboration

Figure 11 shows the pressure contours on the outside of the Tesla. It is observed that the highest pressure by the wind is in the front part (color rojo) with a value of $102051.95 \mathrm{~Pa}(1.02$ bar) and the lowest pressure is $100087.09 \mathrm{~Pa} \mathrm{(1}$ bar) at speed of $250 \mathrm{~km} / \mathrm{h}$.

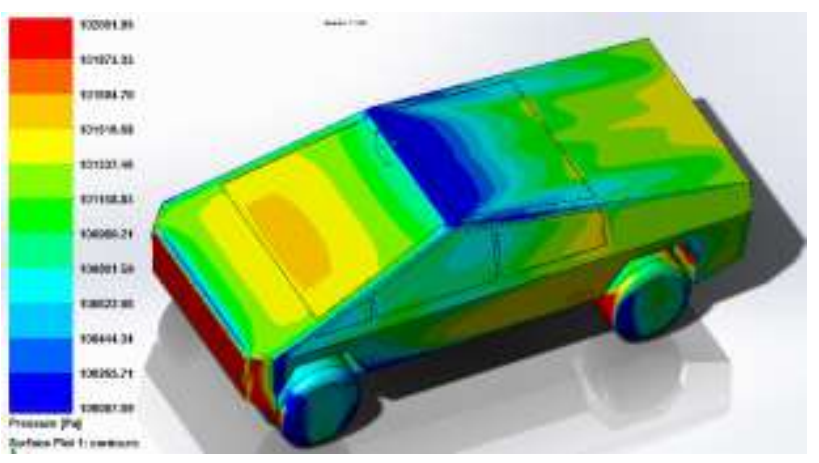

Figure 11 Results of the pressure contours at speed of 250 $\mathrm{km} / \mathrm{h}$ obtained in Solidworks simulation

Source: Own Elaboration

The speed contours are shown in Figure 12 simulated at the speed of $250 \mathrm{~km} / \mathrm{h}$; it is observed that in the rear part the wake of vortices is formed with low speeds that cause the pressure to decrease.

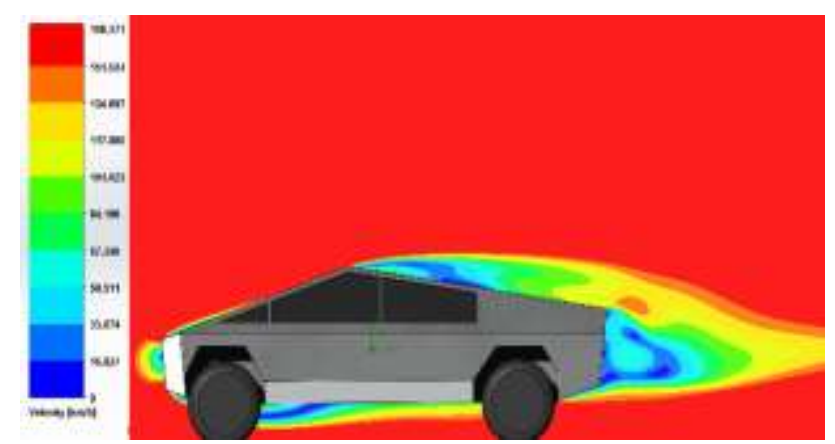

Figure 12 Results of the speed contours obtained in Solidworks simulation

Source: Own Elaboration 


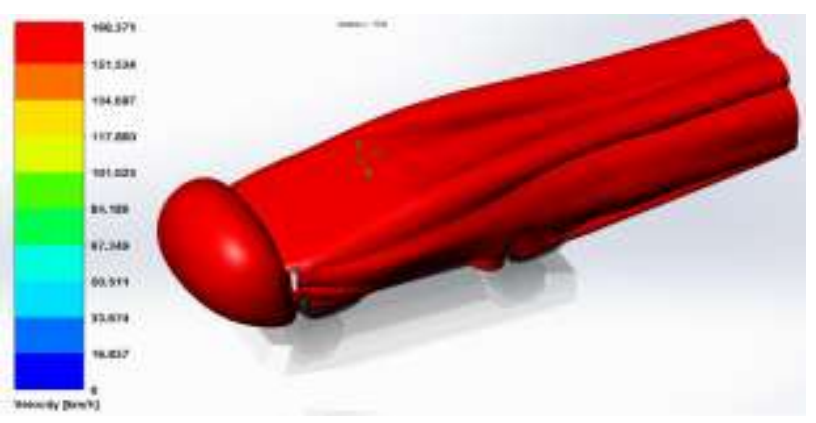

Figure 16 Results of the speed contours $250 \mathrm{~km} / \mathrm{h}$ obtained in Solidworks

Source: Own Elaboration

\section{Conclusions}

Making a comparison of the results of the drag coefficient of the Tesla Cybertruck and data of some cars shown in Figure 3, it is concluded that the Tesla car has a design that guarantees excellent aerodynamic results with an average drag coefficient in a range of $0.3-0.4$, the Tesla model S (2012) has a drag coefficient of 0.24 and 0.189 for the Volkswagen.

The results of the lift coefficient were obtained an average of 0.11 , a very low coefficient that guarantees the stability of the Tesla. On the part of the computer equipment, while the mesh is finer the longer it will take to solve the simulation and the results will be more exact to reality depending on the characteristics of the computer.

\section{Referencias.}

[1] https://www.tesla.com/es_MX/cybertruck

[2] Sisson, Richard. 2007. The American Midwest: An Interpretive Encyclopedia. Ed. Indiana University Press, 1a edition, pp. 14231424.

[3] Gunnell, John., 2003. Standard Catalog of Chevrolet 1912-2003. Ed. Krause Publications, 3a edition, pp. 12-13.

[4] Gunnell, John., 2008. Standard Catalog of Ford. Ed. Krause Publications, 1a edition, pp. 12.

[5] Mohamed-Kassim Z., Filippone A., 2010. Fuel savings on a heavy vehicle via aerodynamic drag reduction. Transportation Research Part D: Transport and Environment. 15 (5), pp. 275-284.
[6] Paolo F., 2009. The effect of the competition between cars and trucks on the evolution of the motorway transport system. Transportation Research Part C: Emerging Technologies, 17 (6), pp. 558-570.

[7] Cooper K. R., 2004. Commercial vehicle aerodynamic drag reduction: historical perspective as a guide. In: The Aerodynamics of Heavy Vehicles: Trucks, Buses and Trains. Springer, Berlin, Heidelberg, pp. 9-28.

[8] Sovran G., 1983. Tractive-energy-based formulae for the impact of aerodynamics on fuel economy over the EPA driving schedules. No. 830304. SAE Technical Paper.

[9] Katz J., 2006. Aerodynamics of race cars. Annu. Rev. Fluid Mech. 38. Pp. 27-63.

[10] Yang Z., Khalighi B., 2005. CFD simulations for flow over Pickup trucks. SAE Paper No. 2005-01-0547.

[11] Al-Garni A., Bernal L., Khallghi B., 2003. Experimental investigation of the near wake of a Pickup truck. In: SAE World Congress, 200401-0228, Detroit, USA.

[12] Holloway S., Leylek J. H., York W. D., Khaligui B., 2009. Aerodynamics of a Pickup truck: combined CFD and experimental study. SAE Int. Journal Commercial Vehicles 2, pp. 88100.

[13] Roshko A., 1993. Perspectives on bluff body aerodynamics. Journal Wind Engineering Industrial Aerodynamic. 49. pp. 79-100.

[14] Choi H., Lee J., Park H., 2014. Aerodynamics of heavy vehicles. Annu. Rev. Fluid Mech. 46. pp. 441-468.

[15] Schuetz T. C., 2015. Aerodynamics of road Vehicles. Fifth ed. SAE International.

[16] R. B. Bird., (1992). Fenomenos de Transporte. Editorial Reverte. Barcelona España.

[18] Hucho W. H., Gilhaus A., Hoffman., (1998). Aerodynamics of a road vehicle. USA: SAE International. 
[19] https://es.paperblog.com/la-resistenciaaerodinamica-y-el-coeficiente-cx-en-elautomovil-4678075/

[20] Robert W. Fox., Alan T. MacDonald., Philip J. Pritchard., 2003. Introduction to Fluid Mechanics, Sixth Edition.

[21] V. Yakhot., L. M. Smith., 1992. The renormalization group, the E-expansion and derivation of turbulence models. Journal of Scientific Computing, Vol. 7, no. 1, pp. 35-61. 